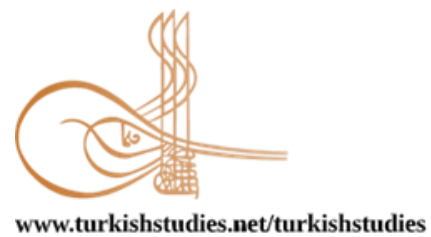

Turkish Studies

\title{
COVID-19 Pandemisi Döneminde Sokağa Çıkma Sınırlaması Olan ve Olmayan İllerde Yaşayan Spor Bilimleri Öğrencilerinin Fiziksel Aktivite Düzeylerinin Değerlendirilmesi
}

\author{
An Evaluation of Physical Activity Levels of Sports Sciences Students Living in Cities with and \\ without Curfew due to COVID-19 Pandemic
}

\author{
Sercan Öncen* - Serkan Aydın** - Erkan Molla***
}

\begin{abstract}
The epidemic of the SARS-CoV-2 virus, which started in China and spread worldwide at a very high rate, has been declared as Pandemic by the World Health Organization (WHO). Because of high contagiousness level of Covid-19 infection, people all around the world have been requested voluntary quarantine practices from their governments and education and training have been interrupted. In order to reduce the rate of infection, central governments applied curfews in highly populated cities during the later periods of the pandemic. This study aims to evaluate the physical activity levels of the participants who study sports sciences and live in cities with and without curfew.131 participants without curfew and 100 participants with curfew were included in the study. The long form of "International Physical Activity Questionnaire" (IPAQ) was used to determine the physical activity levels. IPAQ data of the participants with and without curfew were obtained concurrently. In the statistical analysis of the obtained data, descriptive statistics and Mann-Whitney U tests were appliedby using IBM SPSS software. The differences in the levels of work-related, transportation, housework and leisure time physical activity of sports sciences students with and without curfew were found respectively as $\% 11,68, \% 42,25, \% 25,14, \% 0,91$. The highest difference between the two groups was observed at the transportation physical activity level as $\% 42.25$. The comparison between participants with and without curfew reveals significant differences in the activity levels of transport (p: 0,015 ; d: 0,463), housework (p: 0,006; d: 455), total amount of sitting time (p: 0,000; d: 0,586), walking (p: 0,$002 ;$ d: 0,625 ) and total physical activity levels (p: 0,041; d: 0,395). A negative significant difference was observed in the physical activity levels of the participants with curfew compared to the participants without curfew according to the IPAQ assessment of the sports sciences studying participants during the pandemic caused by the COVID-19 infection. It is important to note that the significant difference in physical
\end{abstract}

*Öğr. Grv. Dr., Tekirdağ Namık Kemal Üniversitesi, Beden Eğitimi ve Spor Yüksekokulu

Lecturer Dr., Tekirdağ Namık Kemal University, School of Physical Education and Sports

ORCID 0000-0001-6147-2966

soncen@nku.edu.tr

** Öğr. Grv., Tekirdă̆ Namık Kemal Üniversitesi, Beden Eğitimi ve Spor Yüksekokulu

Lecturer, Tekirdă̆ Namık Kemal University, School of Physical Education and Sports

ORCID 0000-0003-3618-8028

saydin@nku.edu.tr

****Yüksek Lisans Öğrencisi, Tekirdağ Namık Kemal Üniversitesi, Sağllk Bilimleri Enstitüsü

M.S.c. Student, Tekirdağ Namık Kemal University, Enstitue of Health Sciences

ORCID 0000-0003-1692-1245

erkanmolla95@gmail.com

Cite as/ Atıf: Öncen, S., Aydın, S. \& Molla, E. (2020). COVID-19 pandemisi döneminde sokağa çıkma sınırlaması olan ve olmayan illerde yaşayan spor bilimleri öğrencilerinin fiziksel aktivite düzeylerinin değerlendirmesi. TurkishStudies, 15(6), 739-749. https://dx.doi.org/10.7827/TurkishStudies.44627

Received/Geliș:29 June/Haziran 2020

Accepted/Kabul:15October/Ekim 2020

Copyright $(\mathrm{C}$ MDE, Turkey
Checkedbyplagiarism software

Published/Yayın: 20 October/Ekim 2020

CC BY-NC 4.0 
activity results from the increased amount of time spent at home and that decreased physical activity can have negative effects on blood glucose level and body composition which may lead to an increased risk of depression and anxiety disorder, and a decrease in quality of life and immune system.

\section{Structured Abstract: Introduction}

The epidemic caused by COVID-19 infection was declared as pandemic on March 11, 2020 by the World Health Organization (WHO, 2020). By May 25th, there were 5,490,954 confirmed cases and 345,962 deaths worldwide, starting in the city of Wuhan, Hubei Province of China, spreading all over the world (WHO, 2020). This rate was noted as 509,164 cases and 23,335 deaths on March 27th (Petersen \& Gökengin, 2020). In 2003, SARS-CoV infection led to 8,098 cases and 774 deaths with a $9.7 \%$ mortality rate (WHO, 2020). While the rate of occurrence of SARS-CoV symptoms is in 6-11 days, the occurrence of SARS-CoV2 symptoms is in 5-6 days which complicates the quarantine practices (Wang \& Zhang, 2020; Cheng et al., 2004; Petersen \& Gökengin, 2020).

Clinical cases of children rarely occur, although transmission rate of SARS-CoV-2 seems similar among adults and children. Also, the high pre-symptomatic carrier rate of children and adolescents makes it difficult to take precautions to prevent transmission. In these cases, national governments decided to shut the schools down. Social isolation and not leaving home unless required were some of the measures to prevent the spread of Covid-19 disease in the community. Due to high density level of population, regional curfews were applied by national governments in order to minimize the contact between people.

The increase in time spent at home has negative effects on physical activity. The effect of physical activity or exercise on the immune system varies depending on the intensity, duration, severity of the activity or exercise and the level of physical fitness of the individual. Regular physical activities have improving and protective effects on all systems in our body, such as our cardiovascular system, respiratory system, musculoskeletal system, endocrine system, strengthening of our immune system, and on our growth and development (Berivanl, 2019).

\section{Purpose}

This study aims to investigate the different physical activity levels of the sports sciences studying participants who live in metropolitan cities with curfew and participants in cities without curfew during Covid19 pandemic declared by World Health Organization resulting from SARS-CoV-2 virus.

\section{Method}

100 participants living in a metropolitan city with curfew studying at the Faculty of Sports Sciences, and 131 participants living in a city with no curfew were included in this study. Relational screening method was used to determine the sample group. Data showing the level of physical activity in the study were obtained concurrently during Covid-19 pandemic period.

The self-report technique used to determine the level of physical activity is one of the acceptable methods for calculating the amount of energy spent during daily activities in large groups. (Ballor et al., 1989; Janz, 1994). The long form of "International Physical Activity Questionnaire" (IPAQ) was used to determine the levels of physical activity of individuals (Craig et al., 2003).

\section{Results}

Examining the differences in the physical activity levels of the Sports Sciences studying participants living in a metropolitan city with curfew and participants living in a city with no curfew in order to determine the changes occurring in the level of physical activity is the focus of this study. There was a significant decrease in the levels of physical activity of the participants living in the city with curfew compared to the participants from the city with no curfew. Statistically significant differences occurred especially in transportation, housework, total sitting time, walking and total physical activity levels.

A significant increase was observed as a result of increased amount of time spent at home during the Covid-19 pandemic period as $59.1 \%$ in the frequency of using social media and $75.8 \%$ in the desire to follow the news (Karataş, 2020) and in sitting at home on the weekdays (d: 0.615), at the weekend (d : 0.520) and in total time (d: 0.586). It was reported that low physical activity level may affect physical and mental health negatively even for short periods of time, and in case of curfew, irregular eating habits and frequent snacks may occur, resulting in a higher risk of calorie intake and obesity (Naja \& Hamadeh 2020). 
The fact that the data used in the study was obtained from a metropolitan city with curfew and a city without curfew leads to limitations in reflecting the population considering that Covid-19 pandemic affects the whole world. Therefore, extending the study by including more regions and different countries will allow a better understanding of the effects of the pandemic on physical activity.

Keywords: Physical education, Physical activity, Covid-19, Pandemic

Öz: Çin'de başlayıp çok yüksek bir hızla dünya geneline yayılan ve COVID-19 enfeksiyonuna neden olan SARS-CoV-2 virüsü salgını, Dünya Sağlık Örgütü (WHO) tarafindan pandemi olarak ilan edilmiştir. Covid19 enfeksiyonu bulaşma özelliğinin yüksek olması nedeni ile hükümetler tarafindan dünya genelinde insanlardan gönüllü karantina uygulamaları istenmiş ve eğitim öğretime ara verilmiştir. Pandeminin ilerleyen dönemlerinde bulaşın azaltılması amacı ile merkezi hükümetler yoğun insan popülasyonlarının bulunduğu şehirlerde sokağa çıkma kısıtlaması uygulamışlardır. Çalışmamızda sokağa çıkma sınırlaması var (SÇV) olan ve herhangi bir sokağa çıkma sınırlaması yok (SÇY) olan illerde yaşayan spor bilimlerinde (SB) öğrenim gören katılımcıların fiziksel aktivite düzeylerinin değerlendirilmesi amaçlanmıştır. Çalışmaya 131 SÇY ve 100 SÇV spor bilimleri öğrenimi gören katılımcı dahil edilmiştir. Fiziksel aktivite düzeylerinin belirlenmesinde "Uluslararası Fiziksel Aktivite Anketi" (IPAQ) uzun formu kullanılmıştır. IPAQ verileri SÇV ve SÇY katılımcılarından aynı anda elde edilmiştir. Elde edilen verilerin istatistiksel analizinde IBM SPSS paket programı kullanılarak tanımlayıcı istatistik ve Mann-Whitney U testleri uygulanmıştır. SB öğrenimi gören SÇV ve SÇY katılımcılarının işle ilgili, ulaşım, ev işleri ve boş zamanlarında gerçekleşen fiziksel aktivite düzeylerinde sırası ile $\% 11,68, \% 42,25, \% 25,14, \% 0,91$ farklılık meydana gelmiştir. İki grup arasındaki en yüksek farklılık ulaşım fiziksel aktivite seviyesinde $\% 42,25$ olarak gözlenmiştir. SÇV ve SÇY değerlendirmesinde ulaşım (p: 0,$015 ; \mathrm{d}: 0,463)$, ev işleri (p: 0,$006 ; \mathrm{d}: 455)$, toplam oturarak geçen zaman (p: 0,$000 ; d: 0,586$ ), yürüyüş (p: 0,002; d: 0,625 ) ve toplam fiziksel aktivite düzeylerinde (p: 0,$041 ; d: 0,395$ ) anlamlı fark vardır. SB katılımcılarının IPAQ değerlendirmesine göre COVID-19 enfeksiyonunun sebep olduğu pandemi sırasında SÇV katılımcılarının SÇY katılımcılarına göre fiziksel aktivite düzeylerinde olumsuz yönde anlamlı bir fark gözlenmiştir. Fiziksel aktivitedeki anlamlı seviyedeki farkın evde geçirilen zamanın fazlalaşmasından kaynaklandığı ve azalan fiziksel aktivitenin kan glikozu seviyesi ve vücut kompozisyonuna olumsuz etkilere, depresyon ve kaygı bozukluğu riskinde artışa, yaşam kalitesi ve bağışıklık sisteminde azalışa neden olabileceği göz ardı edilmemelidir.

Anahtar Kelimeler: Beden eğitimi, Fiziksel aktivite, Covid-19, Pandemi

\section{Giriş}

COVID-19 enfeksiyonunun sebep olduğu salgın Dünya Sağlık Örgütü tarafından 11 Mart 2020 tarihinde pandemi olarak ilan edilmiştir (World Health Organization, 2020). Çin'in Hubeieyaleti, Wuhan kentinde başlayarak tüm dünya geneline yayılan salgın sebebi ile 25 Mayıs tarihi itibari ile dünya genelinde 5.490.954 doğrulanmış vaka ve 345.962 ölüm gerçekleşmiştir (World Health Organization, 2020). Bu sayı 27 Mart tarihinde 509.164 vaka ve 23.335 ölüm olarak not edilmiştir (Petersen \& Gökengin, 2020). 2003 yllında SARS-CoV enfeksiyonu \%9,7 lik ölüm oran1, 8,098 vaka ve 774 ölüme sebebiyet vermiştir (World Health Organization, 2020). Dünya Sağlık Örgütü tarafından SARS-CoV-2 virüsünün yakın temasla bulaşıc1lık özelliğinin yüksek olduğu (World Health Organization, 2020) ve kuluçka süresinin ortalama 5-8 gün olduğu tanımlanmıştır (Backer vd., 2020). Ayrıca SARS-CoVvirüsünden kaynaklanan semptomların ortaya çıkma süresi 6-11 gün iken SARS-CoV-2 virüsünden kaynaklanan semptomların ortaya çıma süresi 5-6 gün olarak gözükmekte ve dolayısı ile karantina uygulamalarını da zorlaştırmaktadır (Wang \& Zhang, 2020; Cheng vd., 2004; Petersen \& Gökengin, 2020).

Ulusal yönetim tarafından pandeminin bölgesel olarak daha yakın yönetilebilmesi adına merkezi İl Pandemi Kurulları (IPK) kurulmuştur. IPKK kendi merkezi yönetimleri içerisinde bulunan bölgelerde virüsün bulaş riskini azaltacak önleyici tedbirler almakla görevli kurumlardır. SARSCoV-2 virüsünün damlacık yoluyla bulaşın kontrol edilebilmesi adına sosyal mesafeyi 1,5 m., hızlı yürüyüşlerde $5 \mathrm{~m}$., tempolu koşularda $10 \mathrm{~m}$. olarak belirlemenin (Öztürk \& Bayraktar, 2020; Nyenhuis vd., 2020) ve bireylerin toplu olarak bulundukları alanlardan uzakdurmalarının 
enfeksiyondan kaçınmada ciddi rolü bulunmaktadır (Wei vd., 2020). Bu nedenle COVID-19 enfekte oranının düşürülebilmesi adına gönüllü karantina uygulamaları ile virüsün yayılması önlenmeye çalışılmıştır. SARS-CoV-2'nin pre-semptomatik vaka durumu, hasta kişilerin erken tespit ve izolasyonunu içeren önleme ölçülerini zorlaştırmaktadır (Wei vd., 2020). Tüm bunlara ek olarak bulaşıcılığın önlenmesinde sosyal izolasyon, kişisel koruyucu ekipmanlar (maske, eldiven, siperlik vb...) ve sosyal mesafeyi koruma $(1,5 \mathrm{~m}$.) gibi insanların birbirleriyle teması kesecekleri yöntemler öncelik kazanmıştır (Deniz \& Kiraz, 2020). İPK bulaşın seyrine göre COVID-19 hastalığının toplumda yayılmasını önleme tedbirleri arasında sosyal izalasyon ve zorunlu olmadıkça evden çıkılmamasını istemiştir. Türkiye Cumhuriyeti sınırları içinde yaşayan 65 yaş üstü ve 20 yaş altı bireylerin evden çıkmaları sınırlandırılmış, 20-65 yaş arası bireyler için de hafta sonu zorunlu karantina uygulaması getirilmiştir. Bu durum bireylerde fiziksel inaktivitede artış meydana getirmesi çok muhtemel bir sonuç olarak değerlendirilmektedir (Caner vd., 2020).

Bireylerin yaşam şekillerine bağlı olarak sergiledikleri fiziksel hareketler bütünü fiziksel aktivite (FA) seviyesini belirlemektedir. Düzenli egzersizin ve fiziksel hareketliliğin yaşam süresi üzerinde olumlu etkileri bulunmaktadır (Paffenbarger vd., 1994; Powell vd., 2011). Dünya Sağlık Örgütünün 2002 yılında yayınladığı rapora göre, hareketsiz yaşam dünya çapında yılda 1,9 milyon kişinin ölümüne neden olmaktadır. Aynı zamanda düşük fiziksel aktivite seviyesi önemli bir halk sağlığı sorunu olarak tanımlanmaktadır. Sağlıksız bir halk, iş üretimini azaltırken, hükümetlerin sağlık harcamalarını da arttırarak boşa kaynak tüketimine sebep olacaktır. Sağlıklı yaşam alanı yüzdesi arttıkça kardiyovasküler rahatsızlık, diyabet ve kansere yakalanma olasılığı gibi hastalık riskleri azalmaktadır. Fiziksel olarak aktif olan ve egzersiz yapan bireyler yapmayan bireylere göre miyokart enfarktüsü (kalp krizi) sırasında \%60 oranında daha düşük bir kalp hasarı yaşamaktadırlar (Borges vd., 2014; Powers vd., 2014). Aynı zamanda fiziksel olarak aktifliğin vücut kompozisyonunda olumlu etkilere, tip II diyabet kan glikozu seviyesinde iyileşmeye (Helmrich vd., 1994), kadınlarda meme ve rahim kanseri yüzdelerinde düşmeye (Kruk\&Czemiak, 2013), depresyon ve kaygı bozukluğu risklerinde azalmaya, yaşam süresinde artışa, psikolojik olarak iyi olma haline ve yaşam kalitesinde yükselişe sebep olduğu gözlenmektedir. Bu nedenle Amerikan Spor Hekimleri Birliği (ACSM) sedanter bireylerin en az haftanın 3 günü 30 dakika orta şiddetli bir egzersiz programı uygulamalarını önermektedir. Orta şiddetli FA maksimum kalp atış hızının (KAHmax) \%55-65' i veya kalp atış rezervinin \%40-50' sin de egzersiz yapma durumu olarak ve sedanter bireylerde aerobik kapasitenin gelişimi için minimum bir eşik şeklinde tanımlanmaktadır (Franklin, 2000).

COVID-19 pandemisi sokağa çıkma sınırlamaları sebebi ile bireylere uzun süre yaşam alanları içerisinde kalmaları konusunda zorunluluklar getirmiştir. Bu zorunluluk sebebi ile sokağa çıkma sınırlaması yaşayan bireylerin herhangi bir sınırlama yaşamayan bireylere göre fiziksel aktivite seviyesinde düşüş yaşayacağı beklenmektedir. Bireylerin içinde bulunacağı inaktivite durumu sonucunda da ACE1 sistemi değişimleri meydana gelmesi çok muhtemel bir sonuç olacaktır. Fiziksel aktivitenin immün sistemin bir destekleyicisi olduğu göz önünde bulundurularak (Fisher \& Heymann, 2020) sokağa çıkma sınırlaması nedeni ile inaktif bir yaşam tarzına sahip olan bireylerde pro-inflamatuar ACE1 sistem etkilemi gözlenmesi muhtemeldir (Kenyon, 2020; Öztürk \& Bayraktar, 2020). Araştırma sonucundaelde edilecek veriler, pandemi döneminde sokağa çıkma sınırlaması yaşayan bireylerin fiziksel aktivite düzeyleri açısından ne seviyede ve hangi alt boyutlarda sorun yaşadıkları konusunda yordama yapmamıza yardımcı olacaktır. Böylelikle inaktiviteden kaynaklanıyor olabilecek sağlıksal sorunların erken dönemde tespit edilerek önleyici tedbirler alınması konusunda öneride bulunma imkanı sağlanacaktır. 


\section{Yöntem}

Çalışmaya sokağa çıkma sınırlaması varolan büyükşehirde yaşayan 100 ve herhangi bir sokağa çıkma sınırlaması olmayan büyükşehir dışında bir ilde yaşayan 131 Spor Bilimleri Fakültesi öğrencisi katılımcı olarak dahil edilmiştir. Örneklem grubunun belirlenmesinde ilişkisel tarama yöntemi kullanılmıştır. Pandemi döneminde fiziksel temastan kaçınılması adına katılımcılardan anket formunu online olarak doldurmaları istenmiştir. Çalışmada fiziksel aktivite seviyesini gösteren veriler COVID-19 pandemi döneminde katılımcılara aynı zaman diliminde uygulanarak elde edilmiştir.

Fiziksel aktivite düzeyini belirlemede kullanılan kendini rapor etme tekniği büyük gruplarda günlük aktiviteler sırasında harcanan enerji miktarının hesaplanmasında kabul edilebilir yöntemlerden biridir (Ballor vd., 1989; Janz, 1994). Bireylerin fiziksel aktivite düzeylerinin belirlenmesinde "Uluslararası Fiziksel Aktivite Anketi" (IPAQ) uzun formu kullanılmıştır (Craig vd., 2003). IPAQ Türkiye geçerlilik ve güvenilirliği Öztürk tarafından yapılmıştır (Öztürk, 2005).

IPAQ da "yürüyüş, orta şiddetli fiziksel aktiviteler, şiddetli fiziksel aktiviteler" harcanan zaman üzerinden değerlendirilmesi ve her bir aktivitenin tek seferde en az 10 dakika yapılıyor olması ölçüt alınmıştır. Fiziksel aktivitelere ilişkin enerji tüketimlerinin hesaplanmasında her bir aktivitenin haftalık süresi (dakika) ile IPAQ için oluşturulan istirahat oksijen tüketimi katları (MET) enerji değerleri çarpılmıştır. Böylece her bir birey için fiziksel aktivitelerine ilişkin enerji tüketimleri MET-dk/haf biriminde elde edilmiştir.

IPAQ FA düzeyini belirleme aktivitenin tipi, süresi, sıklığı ve şiddeti ana başlıkları altında bilgi toplanabilmesi sayesinde ortaya çıkan metabolik eşitlik (MET) skoru ile mümkün olabilmektedir. MET vücut ağırlığının kilogramı başına 1 saatte, 1 dakikada veya 24 saatte harcadığ 1 enerji olarak tanımlanmaktadır. Bu tanımlama ortalama bir birey için spesifik bir aktivitenin metabolik hızının istirahat metabolik hızına bölünmesine yani 1 MET istirahat oksijen tüketimine eşittir. Ortalama olarak dakikada 200-250 ml. O2 tüketildiğinden, 2 MET’ lik iş için istirahatın 2 misli veya $500 \mathrm{ml}$. oksijen tüketimi gerekmektedir. Yürüme, bisiklet sürme, ev işi yapma, bahçe işi yapma gibi aktivite türlerinin ve şiddetlerinin farklılık gösterdiği durumlardaki enerji harcamalarında (kj/dk) veya oksijen tüketimlerinde FA, MET değeri değişkenlik gösterebilir. Ainsworth ve arkadaşlarının 1987 de yayınladıkları ve 2000 yılında revize ettikleri çalışmada farklı fiziksel aktiviteler için MET değerleri eşdeğerlikleri hesaplanmıştır. (Ainsworth vd., 2000).

\section{Fiziksel aktivite değerlendirmesi}

Aşağıda belirtilen fiziksel aktivite değerlendirmeleri sayesindeI PAQ veri işleme ve analizi rehberi, katılımcıların fiziksel aktivite etki alanlarının (yürüme, orta şiddetli, şiddetli fiziksel aktivite) ve toplam fiziksel aktivite düzeylerinin belirlenmesi sağlanmıştır. IPAQ MET-dk. skorlarının belirlenmesinde katılımcılar $60 \mathrm{~kg}$ standart bireyler olarak değerlendirilmiştir. Kilo farklarından oluşabilecek hesaplama hatalarını ortadan kaldırabilmek için kilogram düzeltmesi [MET- dk.* (kişinin vücut ağırlığı (kg.) / 60 kilogram)] formülü kullanılmıştır.

IPAQ verilerinin analizi için; yürüme 3,3 MET, orta şiddetli fiziksel aktivite 4,0 MET, ulaşımda bisiklet kullanımı 6,0 MET, evin içinde orta derece fiziksel aktivite için 3,0 MET, bahçe işleri şiddetli fiziksel aktivite 5,5 MET ve şiddetli fiziksel aktivite 8,0 MET değerleri kullanılmıştır.

IPAQ hafta içi ve hafta sonu oturarak zaman geçirme sorusu fiziksel aktivite düzeyini belirleme noktasında hesaplamaya dahil edilmeyen ek bir bilgilendirme değeridir.

Elde edilen verilerin istatistiksel analizinde IBM SPSS paket programı kullanılmıştır. Uygulanan normallik testi sonrasında grupların karşılaştırılmasında Mann-Whitney U analizi kullanılmıştır. Etki büyüklükleri Fritz ve arkadaşları tarafından geliştirilen Cohen's d formülü kullanılarak belirlenmiştir (Fritz vd., 2012). Anlamlılık düzeyi $\mathbf{p}<0,05$ olarak kabul edilmiştir. 


\section{Bulgular}

Tablo 1: Katılımcıların tanımlayıcı istatistik verileri

\begin{tabular}{|c|c|c|c|c|c|c|}
\hline & & $\mathbf{N}$ & Ort & SS & Min & Maks \\
\hline \multirow[t]{2}{*}{ Yaş (y1l) } & SÇY & 131 & 20.3 & 2.42 & 19 & 23 \\
\hline & SÇV & 100 & 21.03 & 2.67 & 19 & 23 \\
\hline \multirow[t]{2}{*}{ Boy (cm.) } & SÇY & 131 & 170.85 & 8.666 & 148 & 193 \\
\hline & SÇV & 100 & 174.15 & 9.419 & 153 & 199 \\
\hline \multirow[t]{2}{*}{ Vücut Ağırlığ (kg.) } & SÇY & 131 & 63.24 & 10.902 & 40 & 110 \\
\hline & SÇV & 100 & 66.82 & 11.932 & 42 & 93 \\
\hline \multirow[t]{2}{*}{ VKI' $\left(\mathrm{kg} . / \mathrm{m}^{2}\right)$} & SÇY & 131 & 21.55 & 2.47 & 16.02 & 29.53 \\
\hline & SÇV & 100 & 21.86 & 2.34 & 16.94 & 29.38 \\
\hline
\end{tabular}

*Vücut Kitle İndeksi

Araştırmaya SÇY olan illerde yaşayan 100 ve SÇV olan illerde yaşayan 131 katılımcı dahil edilmiştir. SÇY katılımcıların yaş ortalamaları20,33 $\pm 2,42$ yıl, SÇV katılımcıların yaş ortalamalarıise $21,03 \pm 2,67$ yıl olarak hesaplanmıştır. SÇY katılımcıların ortlama boy uzunlukları $170,85 \pm 8,666 \mathrm{~cm}$., vücut ağırlıklarının $63,24 \pm 10,902 \mathrm{~kg}$. ve vücut kitle indekslerinin $21,55 \pm$ $2,47 \mathrm{~kg} . / \mathrm{m}^{2}$, SÇV katılımcıların ortalama boy uzunluklarını $174,15 \pm 9,419 \mathrm{~cm}$., vücut ağırlıklarının 66,82 $\pm 11,932 \mathrm{~kg}$.ve beden kitle indekslerinin $21,86 \pm 2,34 \mathrm{~kg} . / \mathrm{m}^{2}$ dir.

Tablo 2: Katılımcıların fiziksel aktivite düzeyleri (FAD)

\begin{tabular}{|c|c|c|c|c|c|c|c|}
\hline Değişken & & & $\mathbf{N}$ & Ort & \pm & Ort. Standart Hatası & Değişim \% \\
\hline \multirow{22}{*}{$\begin{array}{l}\text { Fiziksel } \\
\text { Aktivite } \\
\text { Düzeyleri }\end{array}$} & \multirow[t]{2}{*}{ İşle İlgili FAD (met) } & SÇY & 131 & 3577 & \pm & 842 & \multirow{2}{*}{11.68} \\
\hline & & SÇV & 100 & 3159 & \pm & 752 & \\
\hline & \multirow[t]{2}{*}{ Ulaşım FAD (met) } & SÇY & 131 & 1020 & \pm & 134 & \multirow{2}{*}{42.25} \\
\hline & & SÇV & 100 & 589 & \pm & 102 & \\
\hline & \multirow[t]{2}{*}{ Ev İşleri FAD (met) } & SÇY & 131 & 1746 & \pm & 205 & \multirow{2}{*}{25.14} \\
\hline & & SÇV & 131 & 1307 & \pm & 198 & \\
\hline & \multirow[t]{2}{*}{ Boş Zaman FAD (met) } & SÇY & 100 & 1757 & \pm & 212 & \multirow{2}{*}{0.91} \\
\hline & & SÇV & 131 & 1773 & \pm & 257 & \\
\hline & \multirow{2}{*}{$\begin{array}{l}\text { Oturma Süresi Hafta } \\
\text { İçi FAD (met) }\end{array}$} & SÇY & 131 & 444 & \pm & 21 & \multirow{2}{*}{32.65} \\
\hline & & SÇV & 100 & 589 & \pm & 17 & \\
\hline & \multirow{2}{*}{$\begin{array}{l}\text { Oturma Süresi Hafta } \\
\text { Sonu FAD (met) }\end{array}$} & SÇY & 131 & 443 & \pm & 21 & \multirow{2}{*}{27.99} \\
\hline & & SÇV & 100 & 567 & \pm & 18 & \\
\hline & \multirow{2}{*}{$\begin{array}{l}\text { Oturma Süresi Total } \\
\text { FAD (met) }\end{array}$} & SÇY & 131 & 888 & \pm & 41 & \multirow{2}{*}{30.29} \\
\hline & & SÇV & 100 & 1157 & \pm & 33 & \\
\hline & \multirow[t]{2}{*}{ Yürüyüş FAD (met) } & SÇY & 131 & 1503 & \pm & 163 & \multirow{2}{*}{36.26} \\
\hline & & SÇV & 100 & 958 & \pm & 163 & \\
\hline & \multirow{2}{*}{$\begin{array}{l}\text { Orta Şiddetli FAD } \\
\text { (met) }\end{array}$} & SÇY & 131 & 2224 & \pm & 268 & \multirow{2}{*}{17.44} \\
\hline & & SÇV & 100 & 1836 & \pm & 271 & \\
\hline & \multirow[t]{2}{*}{ Şiddetli FAD (met) } & SÇY & 131 & 1629 & \pm & 247 & \multirow{2}{*}{42.60} \\
\hline & & SÇV & 100 & 2323 & \pm & 375 & \\
\hline & \multirow[t]{2}{*}{ Toplam FAD (met) } & SÇY & 131 & 4006 & \pm & 512 & \multirow{2}{*}{17.19} \\
\hline & & SÇV & 100 & 3317 & \pm & 564 & \\
\hline
\end{tabular}

Katılımcıların SÇV ve SVY arasındaki IPAQ değerlendirmelerine göre toplam fiziksel aktivite düzeyinde SÇV de \%17,19 düşüş bulunmaktadır. Toplam FA yı oluşturan yürüme, orta şiddetli FA parametrelerinin her birinde sirası ile \%36,26, \%17,44 fark bulunmaktadır. Evde geçirilen zamanın artması SÇV katılımcılarının oturma süresi hafta içi, oturma süresi hafta sonu ve toplam oturma süresinde sirası ile $\% 32,65, \% 27,99, \% 30,29$ luk artış gerçekleşmiştir. Katılımcıların işte ilgili FA \%11,68, ulaşım ile ilgili FA \%42,25 ve evişleri ile ilgili FA \%25,14 parametrelerinde SÇV katılımcılarının SÇY katılımcılarına göre daha düşük FA seviyesine sahip olduğu gözlenmektedir. 
Tablo 3: Katılımcıların öğrenim gördükleri bölümlere göre dağılımı

\begin{tabular}{|c|c|c|c|}
\hline & $\mathbf{N}$ & 1. Yöneticilik Böl. & 2. Öğretmenlik Böl. \\
\hline SÇY & 131 & 56 & 75 \\
\hline SÇV & 100 & 59 & 41 \\
\hline
\end{tabular}

Araştırmaya dahil edilen 131 SÇY katılımcının 56' sı Spor Yöneticiliği Bölümünde, 75' i Beden Eğitimi Öğretmenliği Bölümünde öğrenim görürken 100 SÇV katılımcının 59' u Spor Yöneticiliği Bölümünde, 41’i Beden Eğitimi Öğretmenliği Bölümünde öğrenim görmektedir.

Tablo 4: Katılımcıların sınıflara göre dağılımı

\begin{tabular}{|c|c|c|c|c|c|}
\hline & $\mathbf{N}$ & 1. SinIf & 2. Sinıf & Sinıf & Sinıf \\
\hline SÇY & 131 & 6 & 34 & 28 & 63 \\
\hline SÇV & 100 & 26 & 32 & 25 & 17 \\
\hline
\end{tabular}

Araştırmaya dahil edilen 131 SÇY katılımcının 6' s1 1. sınıf, 34' ü 2. sınıf, 28' i 3. sınıf, 63' ü 4. sınıf öğrencisi olup 100 SÇV katılımcının 26' sı 1. sınıf, 32' si 2. sınıf, 25' i 3. sınıf, 17' si 4. sinıf öğrencisidir

Tablo 5: SÇV ve SÇY katılımcılarının fiziksel aktivite düzeylerinin değerlendirilmesi

\begin{tabular}{|c|c|c|c|c|c|c|c|c|}
\hline Değişken & & & $\mathbf{N}$ & Rank & $\mathbf{U}$ & $\mathbf{Z}$ & $\mathbf{p}$ & $\begin{array}{c}\text { Cohen's } \\
\text { d }\end{array}$ \\
\hline \multirow{22}{*}{$\begin{array}{l}\text { Fiziksel } \\
\text { Aktivite } \\
\text { Düzeyleri }\end{array}$} & \multirow[t]{2}{*}{ İşle İlgili FAD (met) } & SÇY & 131 & 26.58 & \multirow{2}{*}{286.000} & \multirow{2}{*}{-0.505} & \multirow{2}{*}{0.614} & \multirow{2}{*}{0.143} \\
\hline & & SÇV & 100 & 24.50 & & & & \\
\hline & \multirow[t]{2}{*}{ Ulaşım FAD (met) } & SÇY & 131 & 64.48 & \multirow{2}{*}{1189.000} & \multirow{2}{*}{-2.421} & \multirow{2}{*}{0.015} & \multirow{2}{*}{0.463} \\
\hline & & SÇV & 100 & 49.27 & & & & \\
\hline & \multirow[t]{2}{*}{ Ev İşleri FAD (met) } & SÇY & 131 & 87.27 & \multirow{2}{*}{2202.000} & \multirow{2}{*}{-2.754} & \multirow{2}{*}{0.006} & \multirow{2}{*}{0.455} \\
\hline & & SÇV & 100 & 67.47 & & & & \\
\hline & \multirow[t]{2}{*}{ Boş Zaman FAD (met) } & SÇY & 131 & 70.54 & \multirow{2}{*}{1964.000} & \multirow{2}{*}{-1.099} & \multirow{2}{*}{0.272} & \multirow{2}{*}{0.191} \\
\hline & & SÇV & 100 & 63.19 & & & & \\
\hline & \multirow{2}{*}{$\begin{array}{l}\text { Oturma Süresi Hafta İçi } \\
\text { FAD (met) }\end{array}$} & SÇY & 131 & 98.85 & \multirow{2}{*}{4303.000} & \multirow{2}{*}{-4.466} & \multirow{2}{*}{0.000} & \multirow{2}{*}{0.615} \\
\hline & & SÇV & 100 & 138.47 & & & & \\
\hline & \multirow{2}{*}{$\begin{array}{l}\text { Oturma Süresi Hafta } \\
\text { Sonu FAD (met) }\end{array}$} & SÇY & 131 & 101.32 & \multirow{2}{*}{4627.000} & \multirow{2}{*}{-3.822} & \multirow{2}{*}{0.000} & \multirow{2}{*}{0.520} \\
\hline & & SÇV & 131 & 135.23 & & & & \\
\hline & \multirow{2}{*}{$\begin{array}{l}\text { Oturma Süresi Total } \\
\text { FAD (met) }\end{array}$} & SÇY & 100 & 99.60 & \multirow{2}{*}{4401.000} & -4.271 & 0.000 & 0.586 \\
\hline & & SÇV & 131 & 137.49 & & -4.211 & & \\
\hline & Yürüyüş FAD (met) & SÇY & 100 & 63.51 & 051500 & 3.107 & 000 & 0625 \\
\hline & & SÇV & 131 & 44.80 & 951.500 & -5.102 & 0.002 & 0.020 \\
\hline & Orta Şiddetli FAD & SÇY & 100 & 87.95 & 2713500 & 1861 & 0063 & 0706 \\
\hline & (met) & SÇV & 131 & 74.20 & 2715.500 & -1.001 & 0.005 & 0.290 \\
\hline & Şiddetli FAD (met) & SÇY & 100 & 59.70 & 1642500 & -1395 & 0163 & 0.250 \\
\hline & & SÇV & 131 & 68.91 & $10+2,300$ & 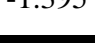 & 0.100 & 0.250 \\
\hline & Toplam FAD (met) & SÇY & 100 & 62.46 & 1212000 & 2048 & 0041 & 0305 \\
\hline & & SÇV & 131 & 49.87 & 1212,000 & -2.040 & 0.041 & 0.593 \\
\hline
\end{tabular}

Katılımcıların SÇV ve SVY arasındaki IPAQ değerlendirmelerine göre ulaşım FA ve ev işleri FA düzeylerinde sırası ile $p=0,015(\mathrm{~d}=0,463), \mathrm{p}=0,006(\mathrm{~d}=0,455)$ anlamlı bir fark $\operatorname{vardır}(\mathrm{p}<0,05)$. Diğer iș ile ilgili $\mathrm{FA}$ ve boș zaman FA düzeylerinde anlamlı bir fark bulunmamaktadır ( $p>0,05)$. Hafta içi oturarak geçen zaman, hafta sonu oturarak geçen zaman ve toplam oturarak geçen zaman değerlendirmesinde sırası ile $p=0,000(d=0,615), p=0,000(d=$ $0,520), \mathrm{p}=0,000(\mathrm{~d}=0,586) \mathrm{SCV}$ katılımcılarının anlamlı bir şekilde daha fazla zaman geçirdiği gözlenmiştir $(p<0,05)$. Katılımcıların SÇV ve SVY toplam FA $(p=0,041 ; d=0,395)$ düzeyleri 
arasında anlamlı fark vardır $(\mathrm{p}<0,05)$. Toplam FA düzeyini oluşturan yürüyüş $F A p=0,002(d=$ $0,625)$ anlamlı bir fark varken $(\mathrm{p}<0,05)$ orta şiddetli FA ve şiddetli FA düzeylerinde anlamlı bir fark bulunmamaktadır $(\mathrm{p}>0,05)$.

\section{Tartışma Sonuç}

Dünya genelinde yaşanan COVID-19 pandemisi sürecinde salgının hızının azaltılması adına ulusal hükümetler tarafından bireylerin yaşam alanlarında geçirdikleri zamanı artırmaları konusunda telkinlerde bulunulmuştur. Ayrıca bulaş riskininin azaltılabilmesi adına sosyal izolasyon ve koruyucu ekipman kullanımının (maske, eldiven, sperlik vb.) önemli olduğu vurgulanmıştır (Güner vd., 2020; Kalebek \& Özdemir, 2020). Bulaş riskinin daha yüksek olarak değerlendirildiği büyükşehirlerde İPK tarafından sokağa çıkma kısıtlaması gibi tedbirler alınarak riskin azaltılması amaçlanmıştır. Bu önleyici tedbirler kapsamında bireylerin yaşam alanlarında geçirdikleri zamanın artmış olması büyükşehirlerde yaşamını sürdüren (SÇV) katılımcılarının fiziksel aktivite düzeylerinde anlamlı seviyede azalışa etkisinin olduğu düşünülmektedir. Özellikle istatistiksel olarak ulaşım, ev işleri, toplam oturarak geçen zaman, yürüyüş ve toplam fiziksel aktivite düzeylerinde anlamlı farklılıklar meydana gelmiştir. SÇV katılımcılarının ulaşımla ilgili fiziksel aktivite düzeyinde meydana gelen $\% 42,25$ farkın pandemi sürecinde bireylerin toplu taşıma araçlarını kullanma davranışlarında ortalama \%95 oranında azalmasından (Karataş, 2020) kaynaklandığı düşünülmektedir. Düşük fiziksel aktivite seviyesinin, kısa süreler için bile fiziksel ve zihinsel sağlığı olumsuz etkileyebileceği, sokağa çıkma sınırlaması durumunda düzensiz yeme alışkanlıkları ve sık atıştırmalar oluşabileceğini böylece de daha yüksek kalori alımı ve obezite riski ile karşı karşıya kalınabileceği vurgulanmaktadır (Naja \& Hamadeh 2020).

COVID-19 pandemi sürecinde bireylerin \%62'sinin sağlıkla ilgili kaygılarının, \%53,5' inin de hastalık belirtileriyle ilgili şüphelerinin arttığını belirterek korona virüsün bulaşma riskinin bireylerde sağlık kaygısına yol açtığı savunulmaktadır (Karataş, 2020). Pandemi sürecinde sağlık ile ilgili kaygı içerisinde olan katılımcılar daha az risk almak amacı ile fiziksel olarak daha inaktif bir yaşam tarzını benimsemiş olabilirler. Bu nedenle özellikle zorunlu karantina dönemlerinde düzenli fiziksel aktivitenin devamlılığının sağlanmasının yanısıra, yoga ve meditasyon gibi uygulamaların hem beden sağlığı hem de ruh sağlığı açısından faydalı olacağ (Acar vd., 2020).

COVID-19 pandemi sürecinde yaşam alanında geçirilen zamanın artması sebebi ile sosyal medyayı kullanma sıklığında \%59,1 lik ve haberleri takip etme isteğinin \% 75,8 lik artış oluşmasına (Karataş, 2020) paralel olarak oturularak geçen hafta içi (d: 0,615), hafta sonu (d: 0,520$)$ ve toplam (d: 0,586) zamanda anlamlı bir seviyede artışın gerçekleştiği gözlenmiştir ( $\mathrm{p}<0,05)$. Bu açıcan kuvvet üretme potansiyelinde hareketsiz geçen her haftata için \%10'a varan genel bir kayıp olduğu kabul edildiği unutulmamalıdır (Varandas vd., 2017; Bilge vd., 2020). UNICEF (2020c) broşüründe bulunan açıklamalarda, dijital araçların çocukların yararına kullanabileceğini ifade ederek çocukları zinde tutacak ve COVID-19 pandemisi süreci öncesindeki hareket etme düzeylerine dönmelerini kolaylaştıracak çevrimiçi egzersiz yayınlarının, fiziksel hareket gerektiren video oyunlarının çocuk tarafından kullanabileceğini ve ailelerin bilgisayar, telefon gibi dijital araçları kullanmasını bu yönde evrimleştirebileceğini belirten hususlara vurgu yapmıştır (Çaykuş \& Çaykuş, 2020; Mart \& Kesicioglu 2020).

Sokağa çıkma sınırlamaları fiziksel aktivite düzeyinde azalmalar meydana getirmiştir. Fiziksel aktivitenin immün sistemde meydana gelen fonksiyon bozukluklarının azaltılmas1, korunması ve immün sistemin bir destekleyicisi olduğu göz ardı edilmemelidir (Fisher \& Heymann,2020). Bu nedenle inaktif bir yaşam tarzına sahip olan bireylerde pro-inflamatuar ACE1 sistem etkilemi gözlenmesi çok muhtemel bir sonuç olacaktır (Abd El-Kader \& Al-Shreef., 2018; Kenyon, 2020; Öztürk \& Bayraktar, 2020; Güneş, 2020). Ek olarak sokağa çıkma sınırlamalarının kardiyovasküler ve diyabet gibi kronik rahatsızlığı olan bireylerin sağlıksal durumları üzerinde olumsuz etkilere neden olması muhtemeldir. Sokağa çıkma sınırlaması sosyal hayatı, yakın 
ilişkileri, ekonomik hayatı olumsuz yönde etkilemiş ve yaşam rutinlerini değiştirmiştir. Salgın riski insanlarda korku, kayg1, öfke gibi olumsuz duyguları tetiklemiştir (Hatun vd., 2020). Fiziksel aktivite düzeyinde meydana gelen azalmalar ve artan oturma süreleri sağlik ile ilgili kaygıların ortaya çıkmasına sebebiyet vermiştir. Düzenli fiziksel aktivitenin depresyon ve kaygı bozukluğu risklerinde azalmaya yol açtığı, uzayan yaşam süresinde, wellness ve yaşam kalitesinde artış meydana getirdiği unutulmamas1 gereken önemli bir unsurdur.

Yapılan araştırmanın özellikle fiziksel aktivite düzeyi yüksek olan spor bilimleri öğrencileri üzerinden gerçekleştirilmesi normal yaşamlarında aktif bir hayat süren bireylerin fiziksel aktivite düzeylerindeki değişimin sokağa çıkma sınırlamaları döneminde ne düzeyde olduğunun daha net bir şekilde tespit edilebilmesi adına önemlidir. Fakat fiziksel aktivite değerlendirilmesinin yapıldığı örneklem grubunun spor bilimleri öğrencileri ile sinırlı tutulması evreni yansıtma konusunda sinırlılıklar barındırabilir. Bu nedenle daha fazla bölgede yaşayan ve farklı çalışma alanlarından bireylerin çalışmaya dahil edilmesi COVID-19 pandemisinin fiziksel aktivite üzerinde meydana getirdiği etkinin daha iyi anlaşılmasına olanak sağlayacaktır.

\section{Kaynakça}

Abd El-Kader, S. M., \& Al-Shreef, F. M. (2018). Inflammatory cytokines and immune system modulation by aerobic versus resisted exercise training for elderly. African Health Sciences, 18(1), 120-131.

Acar, T., Demirel, E. A., Afşar, N., Akçalı, A., Demir, G. A., Alagöz, A. N., ... \& Bilgiç, B. (2020). Nörolojik Bakış Açısından COVID-19. Turk J Neurol, 26, 56-106.

Ainsworth, B. E., Haskell, W. L., Whitt, M. C., Irwin, M. L., Swartz, A. M., Strath, S. J. \&Jacobs, D. R. (2000). Compendium of PhysicalActivities: an Update of Activity Codesand MET Intensities, Medicine and Science in Sports and Exercise, 32(9; SUPP/1), 498-504.

Avcıŏglu K, N., Özdemir, G. (2020). Covid-19 pandemisinin giyim kuşama tematik yansımaları: Maske kullanımı. Turkish $\quad$ Studies, $15(4), \quad$ 57-68. https://dx.doi.org/10.7827/TurkishStudies.43966

Backer, J. A., Klinkenberg, D., \& Wallinga, J. (2020). The incubation period of 2019-nCoV infections among travellers from Wuhan. China. Med Rxiv, 27, 2020.

Ballor, D. L., Burke, L. M., Knudson, D. V., Olson, J. R., \&Montoye, H. J. (1989). Comparison of three methods of estimating energy expenditure: Caltrac, heart rate, and video analysis, Research Quarterly for Exercise and Sport, 60(4), 362-368.

Bilge, M. \& Deliceoğlu, G. \& Işık, Ö. (2020). Covid-19 Pandemi Sürecinde Evde Uygulanan Yüksek Yoğunluklu Aralıklı Antrenmanlar Profesyonel Hentbol Oyuncularının Formda Kalmalarını Sağlayabilir mi? Turkish Studies, 15(4), 1395-1407. https://dx.doi.org/10.7827/ TurkishStudies.44318

Borges, J. P., Verdoorn, K. S., Daliry, A., Powers, S. K., Ortenzi, V. H., Fortunato, R. S. (2014). Delta Opioid Receptors: The link between exercise and cardio protection, Plos One 9(11): e113541, https://doi.org/10.1371/journal.pone.0113541.

Caner, Z. G., Ünal, M., Apaydın, Z., Dağ, A., Okur, Ş., Kara, E., \& Bildik, C. (2020). COVID-19 Hastalığ 1 ve ev egzersizlerinin önemi. Journal of Medical Sciences, 1(3), 25-33.

Cheng, P. K., Wong, D. A., Tong, L. K., Ip, S. M., Lo, A. C., Lau, C. S., ... \& Lim, W. W. (2004). Viral shedding patterns of coronavirus in patients with probable severe acute respiratory syndrome. The Lancet, 363(9422), 1699-1700 
Craig C. L., Marshall A. L., Sjostrom M., Bauman A. E., Booth M. L. and Ainsworth B. E. (2003). International Physical Activity Questionnaire: 12-Country reliability and validity, Medicine Science and Sports Exercise, 35: 1381-95.

Çaykuş, E. T. \& Çaykuş, T. M. (2020). COVID-19 pandemi sürecinde çocukların psikolojik dayanıklılığını güçlendirme yolları: Ailelere, öğretmenlere ve ruh sağlığı uzmanlarına öneriler. Avrasya Sosyal ve Ekonomi Araştırmaları Dergisi, 7(5), 95-113.

Deniz, P. Ö. \& Kiraz, E. D. E. (2020). COVID-19 Pandemi Sürecinde Şehir Sağlığ Çalışmaları. Journal of Biotechnologyand Strategic Health Research, 4, 147-151.

Fisher, D., \& Heymann, D. (2020). Q\&A: The novel coronavirus outbreak causing Covid-19. BMC Medicine, 18(1), 57.

Franklin B. A. (2000). ACSM's Guide Lines for Exercise Testing and Prescription, Philadelphia: Lippincott Williams \&Wilkins.

Fritz, C. O., Morris, P. E., \& Richler, J. J. (2012). Effect size estimates: currentuse, calculations, and interpretation. Journal of Experimental "Psychology: General, 141(1), 2.

Güner, R., Hasanoğlu, İ., \& Aktaş, F. (2020). Covid-19: Prevention and control measures in community. Turk J Med Sci. 21;50(SI-1):571-577.doi: 10.3906/sag-2004-146.

Güneş, A. G. M., Demirer, A. G. B., \& Şimşek, A. G. A. (2020). Bölüm 3 COVID-19 özelinde immün sistemi güçlendirici beslenme ve fiziksel aktivite stratejileri. Ulutaşdemir N. (Ed) Covid 19 Tedavi Belirleyicileri, (1. basım, ss. 125-157). İksad yayınevi

Hatun, O., Dicle, A. N. \& Demirci, İ. (2020). Koronavirüs salgınının psikolojik yansımaları ve salgınla başa çıkma. Turkish Studies, 15(4), 531-554. https://dx.doi.org/10.7827/ Turkish Studies.44364

HELMRICH, S., RAGLAND, D., \& PAFFENBARGER, R. (1994). Prevention of non-insulindependent diabetes mellitus with physical activity. Medicine \& Science in Sports \& Exercise, 26(7), 824-830.

Janz, K. F. (1994). Validation of the CSA accelerometer for assessing children's physical activity. Medicine \& Science in Sports \& Exercise. https://doi.org/10.1249/00005768199403000-00015

Karataş, Z. (2020. COVID-19 Pandemisinin toplumsal etkileri, değişim ve güçlenme social impacts of COVID-19 pandemic, change and empowerment. Sosyal Hizmet Araştırmaları Dergisi. $4(1), 3-15$

Kenyon, C. (2020). The Forrest Gump approach to preventing severe COVID-19-reverse the predisposing pro-inflammatory state with exercise. Microbes and Infection.

Kruk, J., \& Czerniak, U. (2013). Physical activity and its relation to cancer risk: updating the evidence. Asian Pac J Cancer Prev, 14(7), 3993-4003.

Mart, M., \& Kesicioglu, O. S. (2020). Parents' opinion to play at home during COVID-19 pandemic. Turkish Studies, 15(4), 945-958. https://dx.doi.org/10.7827/TurkishStudies. 44381

Naja, F., \& Hamadeh, R. (2020). Nutrition amid the COVID-19 pandemic: a multi-level framework for action. European Journal of Clinical Nutrition, 1-5.

Nyenhuis, S. M., Greiwe, J., Zeiger, J. S., Nanda, A., \& Cooke, A. (2020). Exercise and fitness in the age of social distancing during the COVID-19 pandemic. The Journal of Allergy and Clinical Immunology in Practice. 8(7): 2152-2155 
Öztürk, M. (2005). Üniversitede eğitim-öğretim gören öğrencilerde uluslararas1 fiziksel aktivite anketinin geçerliliği ve güvenirliği ve fiziksel aktivite düzeylerinin belirlenmesi. (Yayımlanmamış Yüksek Lisans Tezi), Ankara: Hacettepe Üniversitesi.

Öztürk, O., \& Bayraktar, D. (2020). Pandemilerin Şafağında: COVID-19 ve Fiziksel İnaktivite. İzmir Katip Çelebi Üniversitesi Sağllk Bilimleri Fakültesi Dergisi, 5(2), 143 146.

Paffenbarger Jr, R. S., Kampert, J. B., Lee, I. M., Hyde, R. T., Leung, R. W., \& Wing, A. L. (1994). Changes in physical activity and other lifeway patterns influencing longevity. Medicine and Science in Sports and Exercise, 26(7), 857-865.

Petersen, E., \& Gökengin, A. D. (2020). SARS-CoV-2 epidemiology and control, different scenarios for Turkey. Turkish Journal of Medical Sciences, 50(SI-1), 509-514.

Powell K. E., Paluch A., Blair S. N. (2011). Physical Activity for Health: What Kind? How Much? How Intense? On Top of What? Annual Review of Puinc Health, 32:349-365.

Powers S. K., Smuder A., Kavazis A. N. \& Quindry C. (2014). Mechanisms of exercise-induced cardioprotection. Physiology, 29:27-38.

Varandas F, Medina D, Gomez A, Della Villa S. (2017). Late rehabilitation (on the field). In: Injury and health problem in football. Springer Berlin Heidelberg; 2017. p. 571-9.

Wang, F. S., \& Zhang, C. (2020). What to do next to control the 2019-nCoV epidemic ?. The Lancet, 395(10222), 391-393.

Wei, W. E., Li, Z., Chiew, C. J., Yong, S. E., Toh, M. P., \& Lee, V. J. (2020). Presymptomatic Transmission of SARS-CoV-2-Singapore, January 23-March 16, 2020. Morbidity and Mortality Weekly Report, 69(14), 411.

World HealthOrganization (2020). Corona virüs disease 2019 (COVID-19), situationreport 67 [online]. Website https://www.who.int/docs/default source/coronavirus/ situationreports/ 20200327-sitrep-67-covid-19.pdf?sfvrsn=b65f68eb_4 [accessed 25 May 2020].

World HealthOrganization (2020). Report of the WHO Chinajointmission on coronavirus disease 2019 (COVID-19) [online]. Website https://www.who.int/docs/default-source/ coronaviruse/who-china-joint-mission-on-covid-19-finalreport.pdf [accessed 29 March 2020].

World HealthOrganization (2020). WHO characterizes COVID-19 as a pandemic [online] Website https://www.who. int/emergencies/diseases/novel-coronavirus-2019/events-asthey-happen [accessed 25 May 2020]. 